This is the pre-peer reviewed version of the following article: "Combined X-ray diffraction and alpha particle X-ray spectrometer analysis of geologic materials", which has been published in final form at [Link to final article using the DOI]. This article may be used for non-commercial purposes in accordance with Wiley Terms and Conditions for Self-Archiving."

\title{
Combined X-ray diffraction and alpha particle X-ray spectrometer analysis of geologic materials
}

\author{
Glynis M. Perrett ${ }^{1 *}$, John A. Maxwell ${ }^{2}$, and John L. Campbell ${ }^{1}$
}

The shallow interrogation depth of the lightest elements ( $\mathrm{Na}, \mathrm{Mg}, \mathrm{Al}, \mathrm{Si}$ ) detected by the PIXE branch of the Curiosity Rover's alpha particle X-ray spectrometer suggests that the X-rays of these elements very likely emerge from a single mineral grain. This reality violates the assumption of atomic homogeneity at the micron scale made in both existing spectrum reduction approaches for the APXS. Consequently, analytical results for these elements in igneous geochemical reference materials exhibit deviations from certified concentrations in a manner that can be related to the TAS diagram. A computer code is introduced here to provide quantitative prediction of these deviations using the mineral abundances determined from XRD. The latter are converted to area coverage fractions to represent the sample surface, and a fundamental parameters computation predicts the elemental X-ray yields from each mineral and sums these. In this process, the chemistry of each individual mineral has to be varied by an iterative Simplex approach; X-ray yields are computed and compared to the peak areas from the fit of the bulk sample. When the difference between mineral yields and peak areas for each element are minimized, the mineral formulae are set and elemental X-ray yields provided. The ratio between the summed mineral X-ray yields and the corresponding yields based on the homogeneity assumption may then be compared directly to the concentration deviations measured in our earlier work. For several rock types, good agreement is found, thereby consolidating our understanding of the effects of sample mineralogy on APXS results.

\section{Introduction}

The Mars Science Laboratory (MSL) Curiosity rover ${ }^{[1]}$ presently in Gale crater, Mars, carries two different instruments for elemental analysis. We are concerned here with one of these, viz. the energy-dispersive "alpha particle X-ray spectrometer” (APXS).

\footnotetext{
* Correspondence to Glynis M. Perrett at Cornell Center for Astrophysics and Planetary Science, Cornell University, Ithaca, NY 14853, USA. Email: gperrett@astro.cornell.edu

${ }^{1}$ Guelph-Waterloo Physics Institute, University of Guelph, Guelph, ON N1G2W1, Canada

247 Surrey St. East, Guelph, Ontario, Canada N1H3P6
} 
The APXS combines X-ray fluorescence (XRF) and particle-induced X-ray emission (PIXE) to generate energy-dispersed $\mathrm{X}$-ray spectra of the elements present in rock and unconsolidated material. Excitation of characteristic X-rays of elements Na-Y is accomplished via a ring of

${ }^{244} \mathrm{Cm}$ radionuclide sources emitting alpha particles and plutonium L X-rays. Spectrometry is accomplished by a silicon drift detector. The instrument interrogates a circular surface area 1.7 $\mathrm{cm}$ in diameter and therefore "averages' over the various minerals present within the rock. It provides an overall estimate of the bulk chemistry in that region. Rieder's detailed description ${ }^{\text {[2] }}$ of the similar APXS carried by the earlier Spirit and Opportunity rovers on the Mars Exploration Rover (MER) mission is an excellent guide to the instrument. A more recent paper by Gellert and Clark ${ }^{[3]}$ provides an overview of the instrument's achievements on both missions. The MSL APXS was calibrated using a suite of approximately sixty geochemical reference materials (GRMs) together with various pure element and chemical compound standards.

There are two methods of interpreting APXS spectra ${ }^{[4,5]}$ and both methods make the assumption that the sample is atomically homogeneous. Given the reality that most geological materials are comprised of a variety of different minerals, each with differing chemistries, this is obviously not often the case. The semi-empirical approach of Gellert et al. ${ }^{[4]}$ developed for the MER APXS has been used, with necessary modifications, for the MSL APXS. It is the source of all MSL APXS data on NASA's Planetary Database ${ }^{[6]}$.The Campbell et al. ${ }^{[5]}$ "fundamental parameters with standards" calibration approach revealed significant and systematic departures of the experimentally-determined concentrations from the official values for the PIXE-excited elements $\mathrm{Na}, \mathrm{Mg}$, and $\mathrm{Al}$ in mafic GRMs. We will refer to these departures as mineral phase effects (MPEs). While these errors could be explained in a qualitative fashion, a quantitative prediction from first principles of such mineral phase effects was lacking. Our main objective in this paper is to develop and test such predictions in the hope that the accuracy of the APXS for these elements can be refined.

\section{Methodology}

Two different approaches to our objective will be discussed. Each of these commences with determination of the GRM modal mineralogy using X-ray diffraction with Rietveld refinement, and each subsequently involves the determination of the chemical make-up of each mineral present. Commonly for minerals present above $5 \%$ mass fraction, the site occupancy factors can be refined to provide more information about the elemental chemistry of the minerals during Rietveld Refinement. However, for our case, these site occupancy factors were not available; only the minerals and their abundances were given. Each approach concludes with a computer prediction for each element of the resulting sum of APXS X-ray yields from those minerals. The ratio of that result to the yield based on the assumption of homogeneity may then be compared directly to the measured mineral phase effects described in Section 3 below.

\subsection{First approach}

We have already reported our first approach ${ }^{[7]}$, which derives from the common practice in geochemical and mineralogical studies of combining bulk chemistry and known mineralogy to obtain a fuller understanding of the material in question. Often, the bulk chemistry is used to 
complement either modal mineralogy from petrographic analyses or mineral abundances determined from XRD patterns; this is particularly useful when the sample has a large amorphous component ${ }^{[8-10]}$.

With one exception, we are not aware of any other program or method that attempts to determine mineral elemental chemistry from known mineral abundances and bulk chemistry. The exception is the code Minlith ${ }^{[11]}$, which is a normative mineralogy program. It uses a set list of minerals, primarily those found in sediments, to determine the best mineralogy of a sediment sample when only the bulk chemistry is known; all mineral formulae are fixed, except for chlorite, in which the $\mathrm{Mg}, \mathrm{Fe}, \mathrm{Al}$, and Si fractions are allowed to vary. In the work reported here all mineral compositions are permitted to vary within geochemically reasonable constraints.

Determination by XRD of the mineral abundances in our GRMs was reported by us earlier ${ }^{[12]}$.The bulk elemental concentrations were taken from the certificates provided by the various GRM suppliers. Our previous attempt to predict mineral phase effects ${ }^{[7]}$ was based on an iterative manual distribution of the bulk elements into the various minerals, the process being informed by geological and geochemical constraints. The iterations were concluded when the sum of distributed elements was within $1 \%$ of the summed bulk elements. At that point, the sum of X-ray yields over all minerals was computed. The method is tedious and due to its manual nature it was restricted to GRMs with simple mineralogy. Moreover, the requirement to know the bulk chemistry in advance restricts its general usefulness.

\subsection{Second approach}

Here, a different starting point was adopted for the calculations in order to remove the requirement for knowledge of the bulk chemistry. A computer program has been developed which requires as input the measured APXS X-ray yields (peak areas) of the material under study. That material can now be either a GRM or an unknown sample. As before, the mineralogy and the mineral abundances have to be determined in advance by XRD. As with the manual method this approach is iterative, but it is now under the control of a recognized optimization technique. The criterion for determining when the optimum result is attained includes the quality of match between measured X-ray yields and predicted yields obtained by adjusting the variable components of the mineral chemistries within reasonable limits.

In the next section the mineral phase effect issue in APXS spectra is outlined. In subsequent sections our second, more generally applicable approach to predicting MPEs is described; its results are compared with those of its predecessor, and more demanding tests than hitherto are reported.

\section{The alpha particle $X$-ray spectrometer: description and calibration}

The treatment of APXS spectra which revealed the mineral phase effects mentioned briefly in Section 1, is a fundamental parameters with standards (FPS) approach using the GUPIX-based spectrum fitting program, GUAPX ${ }^{[5,13]}$. This FPS approach is similar to the method used to 
calibrate the MER APXS instruments ${ }^{[3]}$ in that both methods use non-linear least-squares fitting to determine peak areas, but the approaches to the matrix corrections that are required to convert peak areas to element concentrations differ considerably. The calibration suite for both methods employed the same sixty GRMs; details of these calibration materials are given in Campbell et $a l .{ }^{[5]}$. Crucially, the two methods share the fundamental assumption that samples are atomically homogenous on the submicron scale. However, the majority of the GRMs used are naturally heterogeneous with a maximum grain size in the region of $100 \mu \mathrm{m}$. Despite the obvious violation of the key assumption required by both spectrum fitting procedures, the use of heterogeneous GRMs was a logical choice for calibration material as the APXS analyzes mineral-containing rocks and unconsolidated material on Mars.

The work reported here is based on the GUAPX approach. Since a detailed description of this method is found in Campbell et al. ${ }^{[5]}$ only a very brief summary needs to be given. The fitted peak area for the principal X-ray line of each element in the energy-dispersed spectrum is expressed as the yield in units of counts. The connection between yield, $Y(Z)$, and concentration, $C_{Z}$, for an element with atomic number $Z$ is given by

$$
Y(Z)=H C_{Z} T F_{A P}(Z)\left\{Y_{1, P I X E}(Z, \text { geom })+f_{L} Y_{1, X R F}(Z, \text { geom })\right\} \varepsilon(Z)
$$

where: $H$ is the instrument constant; $T$ is the duration of the measurement; $f_{L}$ is the fraction of alpha decays in which a plutonium $\mathrm{L} X$-ray is emitted; $F_{A P}(Z)$ includes various $\mathrm{X}$-ray physics parameters for sample element $Z$; and $\varepsilon(Z)$ is the relative detection efficiency $(\sim 1.0$ in the energy region $5-10 \mathrm{keV}$ ) calculated from the silicon wafer thickness, beryllium window thickness, and length and pressure of the internal nitrogen column. The $Y_{1}$ terms are the theoretical X-ray yields per unit concentration per unit time per unit solid angle predicted via matrix effect calculations for both PIXE and XRF; each is a function of the measurement geometry and of the concentrations of all elements present in the sample. The solution of equation (1) within GUAPX must therefore be accomplished by iteration of the elemental composition, with the least-squares fit being optimized within each matrix iteration. The sum of element concentrations, including cation-bound oxygen, is normalized to $100 \%$ mass fraction.

The ratio $R$ between the concentrations derived by GUAPX and those recommended by the suppliers of the GRMs was generally close to 1.0, with some notable exceptions for the lightest elements detected. In Figures 1 and 2 we plot the results for Si and $\mathrm{Al}$ in igneous rocks versus the Fe concentration. Minor adjustments have been made relative to similar figures in Campbell et al. ${ }^{[5]}$ : bauxite has been re-classified from 'other' to mono-mineralic, as has a hornblendite GRM previously considered as ultra-mafic. At first sight the choice of abscissa may appear surprising, since the more natural plot would be against the concentration of the element involved, as used by us in Campbell et al. ${ }^{[5]}$. However, the magnitudes of MPEs observed in that work reflected the evolution of the rock type from felsic (low Fe) to mafic (high Fe), which suggests the utility of the present choice. This presentation was suggested to us by P. L. King (private communication) on the basis of the obvious analogy with the widely used total-alkali-silicates diagram ${ }^{[14]}$. 


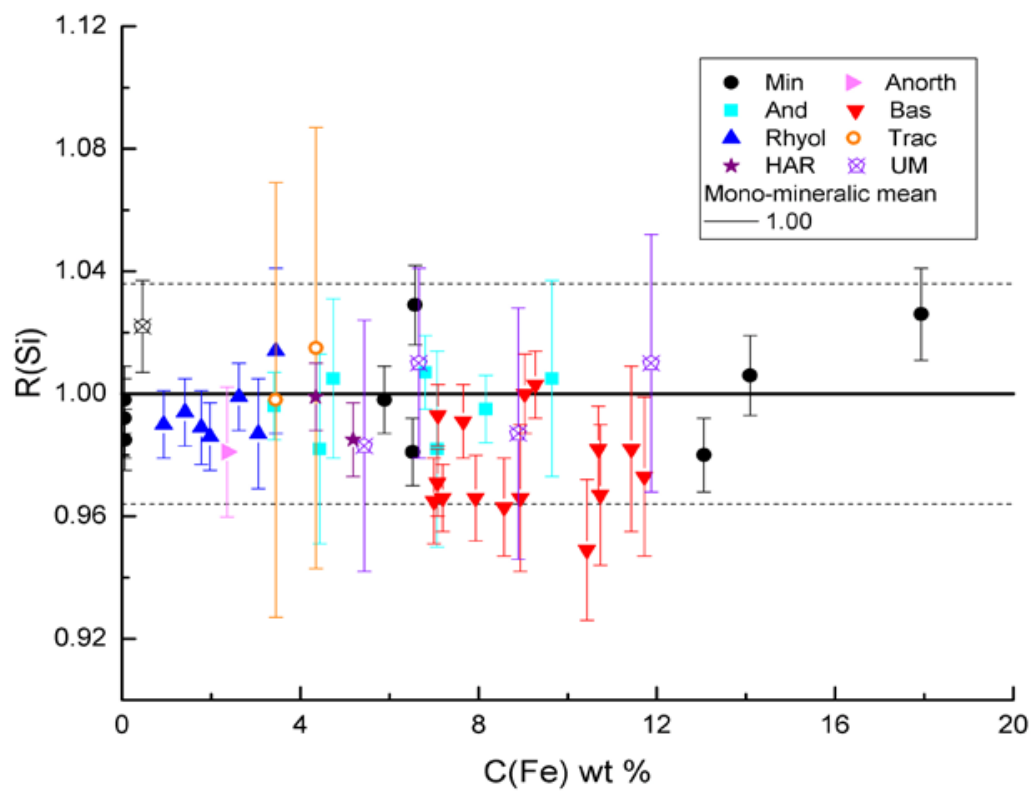

Figure 1. Ratio of Si R-value to Fe concentration for geochemical reference materials grouped as monomineralic, anorthite, andesite, basalt, rhyolite, trachyte, ultra-mafic and high-alkali rock. No significant rocktype dependence is observed.

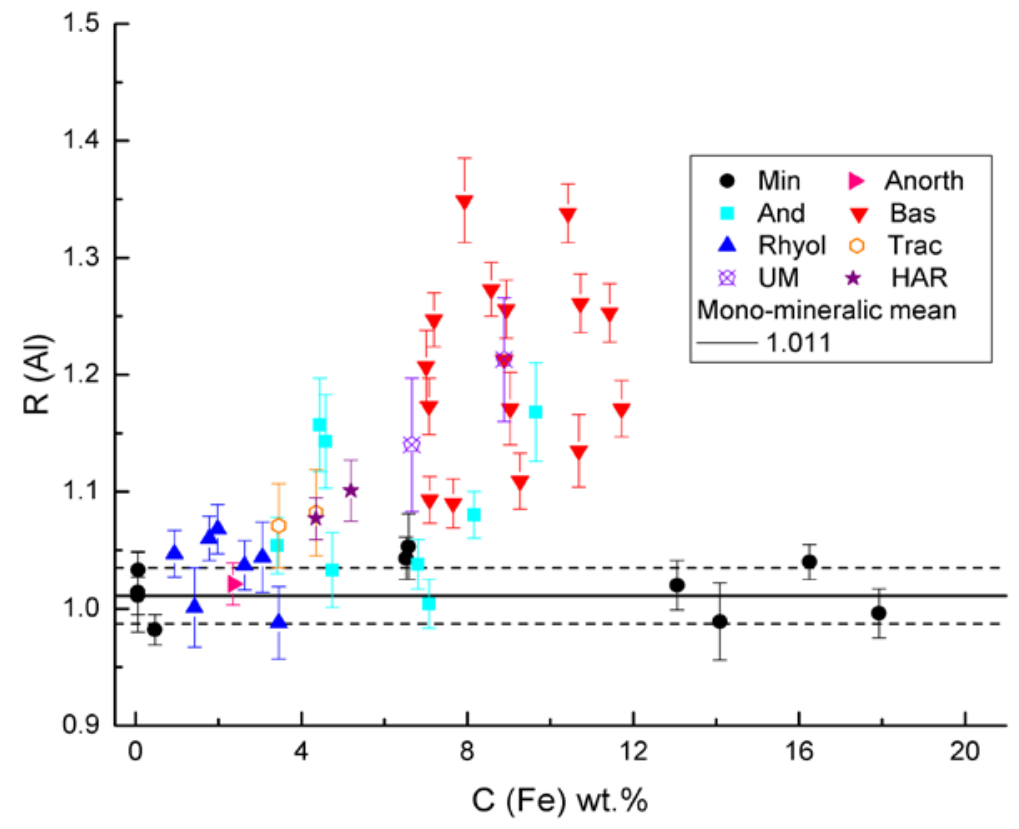

Figure 2. Ratio of Al R-value to Fe concentration for geochemical reference materials classified as in Figure 1. Deviations from $\mathrm{R}=1$ increase as the materials become more mafic. 
$R(\mathrm{Si})$ is almost independent of rock type; the weighted mean $R(\mathrm{Si})$ value for the mono-mineralic subset of GRMs (black circles) is $1.00 \pm 0.04$ (2 SD). In contrast, $R(\mathrm{Al})$ displays a strong trend with rock type. The reality of this igneous rock trend is supported by the near-constancy of $R(\mathrm{Al})$ for the mono-mineralic samples, whose mean is $1.01 \pm 0.04$. Sodium behaves very similarly to $\mathrm{Al}$, while $\mathrm{Mg}$ shows a decreasing relationship between $R(\mathrm{Mg})$ and the Fe content ${ }^{[5]}$. The slightly depressed $R(\mathrm{Si})$ values for basalts, which are evident in Figure 1, may in part reflect the effect of the overall increase in the deduced concentrations for $\mathrm{Na}, \mathrm{Mg}$, and $\mathrm{Al}$ within the necessary normalization to $100 \%$ mass.

The "best" values for these three elements were originally determined as the mean over select GRMs from the calibration that do not appear to display mineral phase effects. In the case of Al

and $\mathrm{Na}$, the "best" value has been adjusted since the values were published in Campbell et al ${ }^{[5]}$; the "best" value is now the mean $R$-value of the mono-mineralic GRMs, since all other GRM categories display MPEs for these two elements. Each measured $R$-value used here was normalized to the "best" value to ensure that it reflected only mineral phase effects (as opposed to instrumental effects such as departures from nominal detector window thickness).

The rising and falling $R$-value trends for $\mathrm{Na}, \mathrm{Mg}$ and $\mathrm{Al}$ in multi-mineralic GRMs relative to mono-mineralic ones were attributed to the location of these elements in specific subsets of minerals, reflecting the heterogeneities of the multi-mineralic rock GRMs. The trends are a direct consequence of the fundamental assumption of equation (1), viz. that all atoms of the sample are distributed homogeneously on the distance scale of the photon and ion interactions. Silicon does not exhibit an analogous trend, likely reflecting the fact that it is the major component of all the silicate GRMs employed. At the time the calibration was published these mineral phase effects were only qualitatively described ${ }^{[5]}$.

\section{Quantitative prediction of mineral phase effects}

\subsection{New basis for calculation of APXS X-ray yields}

The trends exemplified by Figure 1 arise because the computation of the theoretical X-ray yields, $Y_{1}(Z)$, in equation (1) takes into account neither the particle size distribution in a GRM, nor the distribution of the element concerned among its constituent minerals. The maximum particle size is typically $75 \mu \mathrm{m}$. For the three light elements of interest here, the PIXE interrogation depth is less than $5 \mu \mathrm{m}$.

It was suggested to us by R.G. Rieder (private communication) that the homogeneity assumption of equation (1) might be averted by considering the interaction of the exciting radiation with individual minerals at the sample surface rather than with a homogenous atomic distribution throughout the interrogated volume. Given the very small PIXE interrogation depth $(2-5 \mu \mathrm{m})$ for the light elements ( $\mathrm{Na}, \mathrm{Mg}, \mathrm{Al}$ ) which display the large mineral phase effects, this appears a useful approach in these cases. It is likely to be less suitable for heavier XRF-excited elements such as Fe if the interrogation depth $(\sim 80 \mu \mathrm{m})$ and mean particle size are in the same order of magnitude. An approach based on the Rieder suggestion will therefore not be a complete 
solution to the violation of the homogeneity assumption, but it offers the possibility of a better understanding of the MPEs in light elements which arise in the current method.

In this work, as in our previous paper, we shall express $Y_{1}(Z)$ for $\mathrm{Na}, \mathrm{Mg}, \mathrm{Al}$ and $\mathrm{Si}$ as

$$
Y_{1}(Z)=\Sigma_{\mathrm{i}} Y_{1, i}(Z) A_{i}
$$

This represents a summation over all minerals (denoted $i$ ) of the individual mineral $Y_{1}$-values multiplied by their surface area occupation fractions, $A_{i}$; obviously the sum of $A_{i}$ is 1.0. In the ideal case, given the area fractions, mineral abundances, and individual mineral chemistries, $Y_{1}$ can be computed using our code APX-Yield ${ }^{[15]}$. This suggests a means of predicting the MPEs that have been observed in Campbell et al. ${ }^{[5]}$ and thus testing the idea embedded in equation (2).

As previously mentioned, in our case the individual mineral chemistries are not known. For each identified mineral, the general chemical formula is known but not necessarily the number of certain of the atoms present. This is the largest challenge in regard to calculating the theoretical $\mathrm{X}$-ray yields ( $Y_{1}$-values) for the independent minerals within a GRM.

The new automated approach employs the APXS spectrum peak areas obtained by fitting with the GUAPX code; these are the primary quantities produced during spectrum fitting. For comparison of peak areas with X-ray yields predicted by the optimization procedure described below; the predicted yields must be corrected for the detector efficiency.

\subsection{Present work: the APXRD code}

In order to match the X-ray yields predicted from the mineral chemistry with the measured yields from the GUAPX processing of the spectrum, an optimization procedure is required to determine the individual mineral chemistries. The variables that must be optimized are contained in and constrained by the mineral formulae, and are referred to as $p$-values. For example, olivine (( $\mathrm{Mg}_{p}$ , $\left.\mathrm{Fe}_{1-p}\right)_{2} \mathrm{SiO}_{4}$ ) has variable $\mathrm{Mg}$ and $\mathrm{Fe}$ in its formula and the sum of these two element fractions, or $p$-values, must be 1.0 .

Generally there will be more parameters $p(i)$ than there are experimental element X-ray yields, making it impossible to find unique solutions for the $p(i)$. However, we can improve the situation by including the constraint equations where the $p(i)$ of each mineral formula add to 1 . In this way we often end up with the number of data points (experimental yields and constraint sums) matching or exceeding the number of unknown parameters leading to more unique solutions. However, even non-unique solutions may be helpful to the analyst.

Given a starting set of assumed $p(i)$ values, theoretical yields for each element can be calculated and compared to the experimental yields. Theoretical yields are calculated on the basis of the principal line counting rate for the specified matrix and APXS radionuclide source. A scale factor is required to compare the theoretical yields to the experimental yields. This is defined as the sum of the experimental yields divided by the sum of the theoretical yields. The experimental yields are the adjusted, corrected principal line yields on a per second basis from the GUAPX fit. The adjustments are for detection efficiency, and corrections are made for peak area offsets due to known spectrum artefacts. 
A least squares fit of the theoretical yields to the experimental yields plus the $p$-sum constraints to unity is then used to search for the optimal set of $p(i)$ values based on a minimum chi-squared value. The weights for each element yield point are based on the percentage error in peak area provided by the GUAPX spectrum fitting code. The analyst has to choose the standard deviation error for the $p$-sum equations. The tolerable $p$-sum errors can be set to 1 for very loose constraints 0.1 for tighter constraints and 0.01 or 0.001 for very restrictive constraints. It is obvious that this "dual chi-squared" definition is very different from the simple chi-squared associated with non-linear spectrum fitting; it follows that its values should only be considered in a relative sense.

After testing various optimization methods, we chose the Nelder-Mead Downhill simplex method, which produced the best results in a timely fashion. The simplex method is designed to optimize $n$ variables of a function without using derivatives ${ }^{[16,17]}$. The $n$ variables are placed on the vertices of a $(n+1)$ polytope. For example, a two-variable simplex in $\mathbb{R}^{2}$ would be represented by a triangle and a three-variable simplex in $\mathbb{R}^{3}$ would be represented by a tetrahedron. The method first constructs an initial $(n+1)$ simplex. The simplex then transforms itself to adapt to the local landscape by reflecting vertices, contracting, expanding, or shrinking. Once the simplex has reached a defined endpoint by either completing a set number of iterations or by reaching a situation where the function is no longer changing, it is terminated and the final values for the $n$ variables are given.

Before APXRD begins the simplex optimization, trace minerals (defined here as mass fraction less than 1\%) are excluded from the input and those with fixed chemical compositions, such as quartz $\left(\mathrm{SiO}_{2}\right)$, are set as constants in the calculations. Only minerals with variable chemistry are left to be optimized by the program, with the adjusted experimental X-ray yields from GUAPX as the benchmark that the program attempts to reproduce.

APXRD runs four sequential simplexes. The accepted variability of the components within the $p$ value sum increases in rigidity from Simplex 1 (100\% variability) to Simplex $4(0.1 \%$ variability). The first three of these proved useful in working towards Simplex 4, from which the final results were extracted. For a unique solution, the number of $p$-values must be less than the number of variable elements plus the number of constraints. The number of constraints represents the number of element pairs that are being optimized by the program. If the number of $p$-values is greater than the sum of the number of variable elements and constraints, APXRD will still produce a result; however, this result will not be unique and could result in mineral concentrations that are geochemically improbable. In such a scenario, the code provides a warning, and geochemically reasonable restrictions need to be enforced by the user.

Mineral element concentrations are the final output of APXRD. Each simplex gives the $p$-values in the mineral formulae and lists element concentrations specific to each mineral. The latter are the basis for calculating theoretical X-ray yields using the APX-Yield code ${ }^{[15]}$, enabling us to better understand the MPEs observed in the MSL APXS calibration.

\section{Comparison of APXRD results to manual iteration results}


APXRD was tested using the five GRMs that were previously studied by us via the manual approach. Table 1 summarizes their mineralogy as determined using X-ray diffraction with Reitveld refinement. The concentrations are expressed relative to surface area as required by equation (2).

The APXRD mineral compositions are compared to the manual results in Table 2 and the APXRD-based $R\left(Y_{1}\right)$-values are compared to the manual $R\left(Y_{1}\right)$-values and calibration $R$-values in Table 3. The reader is reminded that $R\left(Y_{1}\right)$ denotes the ratio between the $\mathrm{X}$-ray yield $Y_{1}$ predicted with, respectively, the summation over minerals and the homogeneous assumption. In all cases the simplex 4 APXRD results have been presented because of the tight restrictions on $p$ value variability.

The granite reference materials GA and GH were selected in the original study because they displayed minimal mineral phase effects (MPEs). APXRD determined the plagioclase composition of GA to be oligoclase and that of GH to be albite, agreeing with the manual results. In the latter calculations, $\mathrm{F}$ was selected over $\mathrm{OH}$ in muscovite for $\mathrm{GH}$ based on the certificate concentrations; in APXRD the program was fixed to assume $\mathrm{OH}$ rather than $\mathrm{F}$. The only other variable mineral that APXRD had to determine was chamosite in $\mathrm{GH}$, and the mineralogy was very similar for both the APXRD and manual cases. Table 3 shows that the manual and APXRD $R\left(Y_{1}\right)$-values for the granites are identical, so the slight variability in the mineralogy summarized in Table 2 has no significant effect on the theoretical $X$-ray yields. The excellent agreement between the $R\left(Y_{1}\right)$-values calculated by hand and by APXRD demonstrates that the code is capable of producing reasonable results for cases where MPEs are expected to be small. This is a valuable test for consistency. Based on this good agreement, we may conclude that the differences observed between the $R\left(Y_{1}\right)$-values and $R$-values are real.

The two trachyte GRMs ISH-G and MDO-G have similar mineralogy (Table 1) but their classifications differ. The first run of APXRD excluded any Si from augite in both trachytes. This was geochemically unreasonable so restrictions were placed on $\mathrm{Si}$, forcing its $p$-value to be between 0.5 and 1.0. These logical restrictions allowed APXRD to produce geologically viable augite concentrations. No other restrictions were enforced on the $p$-values. The plagioclase of ISH-G was found to be labradorite and that of MDO-G to be bytownite. The elemental compositions, along with the other optimized compositions of anorthoclase and augite in both GRMs, are reasonable. The anorthoclase and plagioclase compositions do not differ greatly from those determined manually. The augite compositions for both MDO-G and ISH-G determined by APXRD do differ significantly from those determined manually. In both manual augite results Ca was the dominant element and Na was completely excluded. The Si abundances were much greater in the by-hand cases, resulting in a much decreased abundance of Al. Comparing the $\mathrm{R}\left(\mathrm{Y}_{1}\right)$-values of both methods to the calibration-determined $R$-values shows that the APXRD program is in better agreement with the $R$-values for MDO-G in all of the light element cases and is also better for $\mathrm{Na}$ and $\mathrm{Si}$ in ISH-G (Table 3 ). These differences in $R\left(Y_{1}\right)$ are reflected in the mineral composition differences between the by-hand calculations and the APXRD program. This indicates that the optimization performed by APXRD is superior to that done by hand when geochemically logical restrictions are enforced on the program. 
The BCR-2 mineralogy used in APXRD was the same as that used in the previous study, viz. the Ca-free pyroxene hypersthene ((Mg,Fe)SiO 3$)$; plagioclase, determined to be labradorite; and elemental Fe (due to milling for the supplier). The resulting mineral formulae from APXRD agree well with those produced manually (Table 2). The APXRD $R\left(Y_{1}\right)$-values are identical to the manually derived $R\left(Y_{1}\right)$-values (Table 3$)$. The only element for which there is not very close agreement between the $R\left(Y_{1}\right)$ from APXRD and the experimental $R$-value is Mg; this is likely due to spectrum fitting issues, given that the weak Mg peak is "sandwiched" between the more intense $\mathrm{Na}$ and the much more intense Al peaks in the BCR-2 spectrum. Use of accelerator-based PIXE with superior energy resolution is planned in the hope of resolving the observed difference. The very good agreement between the APXRD Na and $\mathrm{Al} R\left(Y_{1}\right)$-values and the calibration $R$ values demonstrates that the high $\mathrm{Na}$ and $\mathrm{Al} R$-values are real mineral phase effects resulting from the heterogeneity of the sample.

A valuable use for the APXRD program that would be too time-consuming to attempt with the tedious by-hand approach is to test different mineral compositions to ascertain how sensitive the theoretical X-ray yields are to element distribution. Table 4 presents $R\left(Y_{1}\right)$-values of BCR-2 with the pyroxene defined first as augite (test 1 ) and then as hypersthene (test 2). For Mg, augite provides better agreement with the $R$-value, but the original choice of hypersthene is much superior for $\mathrm{Na}$ and $\mathrm{Al}$. This test demonstrates that the program is sensitive to user input and requires that the user either have accurate mineralogy and bulk chemistry beforehand, or that they have an a priori understanding of the sample's geologic context and are able to produce various scenarios before selecting the correct mineral combination. The Mg result also suggests the need for sensitivity to the accuracy of spectrum fitting, and re-emphasizes the need to repeat some of this work with a laboratory PIXE system having the best possible energy resolution.

The indication of elemental Fe in BCR-2 was at first sight surprising. However, the elemental Fe is attributed by the supplier to the particular grinding process that was employed (private communication with S. Wilson, USGS). Nevertheless, we used the APXRD code to determine what effect removing elemental Fe from the mineral list would have on the theoretical X-ray yields. Doing this forced the clinohypersthene to take up more Fe, with a consequent large reduction of the $\mathrm{Mg} R\left(Y_{1}\right)$-value. The most significant outcome was an inability of the program to distribute $\mathrm{Al}$ and Si properly; Si was grossly over-used when compared to the bulk chemistry of BCR-2, while Al was hardly incorporated into the mineralogy. The Si $R\left(Y_{1}\right)$ value increased from 1.01 to an unacceptable 1.23 .

\section{Application of APXRD to basalt, andesite, and anorthite GRMs}

With a degree of credibility established for APXRD, GRMs with more complex mineralogy than those of Section 4 may be studied. The mineral areal abundances of six GRMs and the APXS basalt calibration target (BT-2) are in Table 5. The emphasis on basalts reflects our interest in the predominantly basaltic Martian targets studied by the APXS.

\subsection{Basalt GRMs}


BHVO-2 (USGS, USA), PM-S (CRPG-SARM, France), and WS-E (CRPG-SARM, France) present MPEs typical of all the basalts used in our APXS calibration, viz. elevated $\mathrm{Na}$ and $\mathrm{Al}$ and depressed Mg experimental concentrations relative to certificate concentrations ${ }^{[5]}$. New Mexico Broken Tank basalt (BT-2) was an obvious test case since it is the calibration target for the MSL APXS ${ }^{[18]}$. Its modal mineralogy was determined by Digitalcore using quantitative evaluation of minerals by scanning electron microscopy (QEMSCAN); results of this analysis were kindly provided by P. L. King (private communication). The sample used to obtain the mineralogy was a polished rock slab, which is now on the MSL rover on Mars. The mineralogy summarized in Table 5 for BT-2 is a renormalization of the data provided by the QEMSCAN analysis after minerals having mass fraction less than $1 \%$ and the "uncharacterized" fraction were removed. The mineral abundances from QEMSCAN are given in terms of area fraction. The mineralogy of the other basalts was expressed as volume fraction so a conversion to surface area fraction was necessary. The APXRD results from simplex 4 were used for all cases because of its tight restrictions on the $p$-values.

In Table 6, simplex $4 R\left(Y_{1}\right)$-values are compared to the calibration $R$-values. The error estimates reflect only the peak area error generated by the non-linear least-squares spectrum fit. Issues such as the lack of a perfectly smooth sample surface suggest that the actual uncertainty will be larger. The mineralogy for BHVO-2 is relatively simple with only two major minerals present. The pyroxene mineral was chosen to be hypersthene and the program was allowed to vary between the Mg end-member, enstatite, and the Fe end-member, ferrosilite ${ }^{[19]}$. No restrictions were placed on the general plagioclase formula, so the $\mathrm{Na}$ and $\mathrm{Ca}$ concentrations could vary as the program saw fit. The final mineral compositions given by APXRD placed the plagioclase composition within the bytownite range (0.7 to $0.9 \mathrm{Ca}$ fraction), a very reasonable plagioclase composition for basalt. The pyroxene concentration was found to be $\mathrm{MgFeSi}_{2} \mathrm{O}_{6}$. The APXRD based $R\left(Y_{1}\right)$-values are in quite good agreement with the calibration $R$-values overall, with the agreement for $\mathrm{Al}$ excellent. The $\mathrm{Na}$ and $\mathrm{Mg} R\left(Y_{1}\right)$ values indicate the presence of MPEs for these two elements and they follow the same directional trends as the calibration $R$-values, without the same level of agreement as $\mathrm{Al}$.

The Pitscurrie microgabbro PM-S from Scotland ${ }^{[20]}$ has relatively complex mineralogy, which required the enforcement of several geochemically reasonable restrictions. Calcium was constrained in plagioclase ( $p=0.5-0.9)$ and Fe was constrained in pyroxene $(p=0.3-1)$, olivine $(p=0.1-0.5)$, amphibole $(p=0.5-0.9)$, and biotite $(p=0.5-0.9)$. The chlorite mineral was assumed to be chamosite $\left(\mathrm{Fe}_{5} \mathrm{Al}_{2} \mathrm{Si}_{3} \mathrm{O}_{10}(\mathrm{OH})_{8}\right)$. APXRD determined plagioclase to be bytownite (Ca fraction of 0.8), pyroxene to be an Fe-containing enstatite ( $\mathrm{Mg}_{1.7} \mathrm{Fe}_{0.3} \mathrm{Si}_{2} \mathrm{O}_{6}$ ), amphibole to be hornblende $\left(\mathrm{Ca}_{2} \mathrm{Mg}_{2.5} \mathrm{Fe}_{2.5} \mathrm{Si}_{3.5} \mathrm{Al}_{4.5} \mathrm{O}_{22}(\mathrm{OH})_{2}\right)$, and olivine and biotite to contain equal portions $\mathrm{Mg}$ and Fe. All of these mineral compositions are reasonable for a basalt. Sodium and $\mathrm{Al} R\left(Y_{1}\right)$ values are in good agreement with the calibration $R$-values. The $\operatorname{Mg} R\left(Y_{1}\right)$ value is somewhat closer to the ideal value of 1.0 than the actual calibration $R$-value; however, both deviate in the same direction, indicating that there is indeed a mineral phase effect present. Many minerals in PM-S contain Mg and Fe and they required the APXRD program to determine the fraction of Mg and Fe in each. Without more detailed mineralogy or sample provenance our results are acceptable and give a clear indication of the presence of mineral phase effects. 
WS-E is a dolerite from the Great Whin Sill, Northern England ${ }^{[21]}$. The only enforced mineral formula restriction was on $\mathrm{Si}$ in pyroxene $(p=0.1-0.8)$. APXRD determined plagioclase to be bytownite (Ca fraction of 0.8), pyroxene to be augite ( $\mathrm{NaFeSi}_{0.5} \mathrm{Al}_{1.5} \mathrm{O}_{6}$ ), amphibole to be hornblende $\left(\mathrm{Ca}_{2} \mathrm{Mg}_{4} \mathrm{Al}_{2} \mathrm{Si}_{7} \mathrm{O}_{22}(\mathrm{OH})_{2}\right)$, and chlorite to be $\mathrm{Mg}_{3} \mathrm{Fe}_{2} \mathrm{Al}_{2} \mathrm{Si}_{3} \mathrm{O}_{10}(\mathrm{OH})_{8}$. Quartz and alkali feldspar (K-feldspar) had fixed formulae. The $R\left(Y_{1}\right)$-values agreed closely with the calibration $R$-values within error for the three lightest elements. Typical basalt MPEs were observed for WS-E and all were replicated with the theoretical X-ray yields.

BT-2 is not a GRM, but its bulk elemental compositions were determined for the MSL APXS team by Activation Laboratories, Ancaster, Ontario, Canada. The only restriction enforced on the BT-2 mineral compositions was on $\mathrm{Mg}$ in augite ( $p=0.6-1.0)$. APXRD results placed the alkali feldspar in the sanidine region with a composition of $\mathrm{Na}_{0.5} \mathrm{~K}_{0.5} \mathrm{AlSi}_{3} \mathrm{O}_{8}$. Plagioclase fell in the bytownite region with a composition of $\mathrm{Ca}_{0.8} \mathrm{Na}_{0.2} \mathrm{Al}_{1.4} \mathrm{Si}_{2.6} \mathrm{O}_{8}$. Olivine was set by APXRD to be more Fe-rich with a composition of $\mathrm{Mg}_{0.1} \mathrm{Fe}_{1.9} \mathrm{SiO}_{4}$. The augite became $\mathrm{CaMg}_{0.9} \mathrm{Fe}_{0.1} \mathrm{Si}_{1.2} \mathrm{Al}_{0.8} \mathrm{O}_{6}$ and the chlorite mineral was primarily chamosite with a small portion of $\mathrm{Mg}$ $\left(\mathrm{Fe}_{4.9} \mathrm{Mg}_{0.1} \mathrm{Al}_{2} \mathrm{Si}_{3} \mathrm{O}_{10}(\mathrm{OH})_{8}\right)$. The albite, analcime, and ulvospinel compositions were fixed. All the lightest element $R\left(Y_{1}\right)$-values agree with the calibration $R$-values within the two standard deviation $R$-value errors. Sodium, $\mathrm{Mg}$, and Al show the typical basalt MPEs for these elements.

In the basalt GRMs overall, the measured $R$-values tend to be very slightly less than 1.0 while the APXRD values of $R\left(Y_{1}\right)$ very slightly exceed 1.0. The first of these two observations likely reflects the consequence of the normalization by GUAPX of oxide mass fractions to $100 \%$, since the overall effect of MPEs on the three lightest elements is an increase in their combined oxide concentration. The slight excess in $R\left(Y_{1}\right)$ for Si probably indicates a real MPE at a level that is not experimentally discernible within our precision.

\subsection{Anorthosite and Andesite GRMs}

Three additional non-basalt GRMs were studied to ascertain if MPE trends other than those expressed by the basalt GRMs could be replicated. AN-G, an anorthosite from Greenland (CRPG-SARM, France) ${ }^{[22]}$, was selected because its $R$-value for Na suggested there was a MPE in the opposite direction to those of the basalts. Two andesites, JA-3 from the Asama volcano, Tsumagoi-mura, Gunma Prefecture (GSJ, Japan) ${ }^{[23]}$ and AGV-2 from Guano Valley, Lake County, Oregon (USGS, USA) ${ }^{[24]}$, were selected because they display different MPE trends to each other, despite belonging in the same rock class. JA-3 displayed similar MPE trends to the basalts, whereas AGV-2 showed a significant MPE only for Mg.

The AN-G $R$-values are less than 1.0 for $\mathrm{Na}$ and $\mathrm{Mg}$, implying that those elements are most likely predominantly in minerals with highly attenuating elements such as Fe. The Al MPE pushes the measured concentration upwards but the effect is minimal. APXRD found the plagioclase composition to be anorthite $\left(\mathrm{Na}_{0.05} \mathrm{Ca}_{0.95} \mathrm{Al}_{2} \mathrm{Si}_{2} \mathrm{O}_{8}\right)$, the amphibole to be hornblende (CaNaMg $2.5 \mathrm{Fe}_{2.5} \mathrm{Al}_{6.4} \mathrm{Si}_{1.6} \mathrm{O}_{22}(\mathrm{OH})_{2}$ ), and chlorite to be $\mathrm{Mg}_{2.5} \mathrm{Fe}_{2.5} \mathrm{Al}_{2} \mathrm{Si}_{3} \mathrm{O}_{10}(\mathrm{OH})$. The $\mathrm{Na}$ to $\mathrm{Ca}$ ratio was fixed for plagioclase to ensure that $\mathrm{Na}$ was included in the composition. In hornblende, Ca was restricted to $p=0.1-0.5$, Si to $p=0.2-0.8$, and $\mathrm{Mg}$ to $p=0.1-0.5$. In chlorite, $\mathrm{Mg}$ was also restricted to $p=0.1-0.5$. If these geochemically reasonable restrictions were not enforced, 
the program was unable to logically distribute $\mathrm{Ca}, \mathrm{Mg}$, and Na. Table 6 shows very good agreement between the predicted X-ray yield ratios and the calibration $R$-values for $\mathrm{Na}, \mathrm{Mg}$, and $\mathrm{Si}$. For Al the small MPE effect plus the error estimate do not provide evidence of disagreement.

The andesite JA-3 displayed MPE trends similar to the standard basalt MPEs with elevated Na and $\mathrm{Al} R$-values and depressed Mg $R$-values. Restrictions were enforced only on Si for all three minerals; $p=0.5-0.75$ for alkali feldspar, 0.2-0.8 for augite, and 0.5-0.75 in plagioclase. The $R\left(Y_{1}\right)$-values agree very well with the calibration $R$-values for $\mathrm{Na}$ and $\mathrm{Mg}$, and reasonably so for $\mathrm{Si}$. For $\mathrm{Al}$ a slight MPE is indicated by the $R\left(Y_{1}\right)$-values, but is not as large as the MPE actually found in the calibration. The Al to Si ratio for all three elements was determined via APXRD. This mismatch between the calibration and theoretical X-ray yields could be an indication that the Al variability was too complex for APXRD and that more information was required to distribute $\mathrm{Al}$ as it exists in the geologic sample.

The measured AGV-2 R-values indicate that only Mg is definitely susceptible to MPEs. APXRD restrictions were enforced on $\mathrm{Mg}(p=0.1-0.5)$ and $\mathrm{Si}(p=0.1-0.9)$ in the pyroxene. The plagioclase mineral composition was determined to be on the andesine-labradorite boundary. The alkali feldspar was determined to be K-feldspar, and pyroxene was classified as augite. The $R\left(Y_{1}\right)$-values match the calibration $R$-values for $\mathrm{Mg}, \mathrm{Al}$, and $\mathrm{Si}$ within the two sigma $R$-value uncertainties. The $R\left(Y_{1}\right)$ value for Na suggests that an MPE should be observable, but the error bar on the smaller measured $R$-value precludes a definitive conclusion for this element. Sodium was allowed to vary in plagioclase, alkali feldspar, and pyroxene. The possible difference between the calibration $R$-value for $\mathrm{Na}$ and the $R\left(Y_{1}\right)$-value perhaps reflects the difficulty the APXRD program had in distributing $\mathrm{Na}$ as it exists in the geologic sample, much like Al for the previous case. More detailed information on this sample's mineralogy would help reduce the uncertainty and complications for the APXRD program.

\section{Conclusions}

The use of a downhill simplex based program to optimize element distribution into minerals has been tested in the APXS context. The APXRD program produces four simplex results with increasing restrictions enforced upon the variables, namely the atom fractions for variable elements in given mineral formulae. The ultimate goal of developing APXRD is to simplify the extensive calculations required to produce mineral elemental concentrations, which are essential for determining the mineral theoretical X-ray yields and ultimately predicting mineral phase effects in APXS analysis of a heterogeneous material. APXRD results for five GRMs having simple mineralogy were in good agreement with results of the previous manual approach ${ }^{[7]}$ and supported the previously observed deviations between the $R\left(Y_{1}\right)$-values and calibration $R$-values.

APXRD was then deployed on six GRMs of more complex mineralogy plus the basalt used for the APXS calibration target. Good agreement resulted between the predicted $R\left(Y_{1}\right)$ values and the calibration $R$-values when error estimates were taken into account for $\mathrm{Na}, \mathrm{Al}$, and $\mathrm{Si}$. For $\mathrm{Mg}$ there is in most cases agreement within rather large error estimates, but there appears to be a trend of the measured $R$-value being less than the prediction. We believe that this systematic effect can be explained by two factors. First, we recall that to accurately represent the mineralogy sampled by the four lightest elements the XRD abundances were converted from 
volume to area with the use of mineral densities. As a result, the denser minerals, i.e. the mafic minerals that contain heavier elements dominated by Fe, had a decrease in areal abundance relative to the volume abundances found by Rietveld analysis. When distributing the bulk chemistry into the mineral formulae as defined by APXRD, elements primarily located in the dense mafic minerals, like Fe and Mg, are under-used. The second factor at play is that the adjustment of mineral abundance from volume to area coverage only accurately describes the lightest, PIXE-excited elements. This scenario is very unlikely to hold for Fe, as we indicated in Section 4. These two effects result in the prediction of less Fe in the mafic minerals to attenuate the $\mathrm{Mg}$ characteristic X-rays. As a result, the predicted $R\left(Y_{1}\right)$ values for $\mathrm{Mg}$ are generally less than those observed in the calibration of our GRMs. Based on these two factors we are satisfied with the results obtained for Mg.

The addition of the very different anorthite to the basalts and the observation of agreement in this case where the MPEs are inverted relative to basalts is a valuable quality check.

Overall, even with the arguments of the prior paragraph regarding Mg, it cannot be a surprise that the agreement in several cases is not perfect. The lightly pressed powder samples by definition do not have smooth surfaces, and the interrogation depth is only a few microns. Particle shape and size may have an influence. The energy resolution is poorer than optimal, which especially impacts the Na-Si region of the spectrum in terms of peak area determination. The mineralogy determined by XRD may not always be fully accurate. A repeat of the work using accelerator-based PIXE with state-of-the-art energy resolution on pellet samples prepared in a high-pressure press would be a useful exercise.

The main outcome is that fundamental predictions of MPEs are in line with observed MPEs for the studied GRMs. This solidifies the idea of using rock type (e.g. basalt) from mineralogy (or just iron content) to determine empirical corrections for MPEs in a given APXS analysis. In turn, this narrows the band of error estimates that is incurred by taking the calibration as an average over many varied rock types.

\section{Acknowledgements}

We first express our sincere thanks to R.G. Rieder for a basic idea which we have employed in this paper. G. Perrett acknowledges support through Canadian Space Agency contract 9F052110786 awarded to the MSL APXS Team at the University of Guelph. The authors appreciate many productive discussions with the APXS Principal Investigator Ralf Gellert and the opportunity to use some of his FEU spectra from the MSL calibration which was supported by the above contract. Development of APXRD was funded by the Natural Sciences and Engineering Research Council of Canada (Discovery grant) and the Canadian Space Agency (grant 09SCIGRA37 awarded to J. L. Campbell). Thanks are also due to Susan Glasauer, Mariek Schmidt, and Penny King for their guidance and discussion, and to Stephen Wilson (United States Geological Survey) for information on the iron impurity in BCR2.

\section{References:}


[1] J. P. Grotzinger, J. Crisp, A. R. Vasavada, R. C. Anderson, C. J. Baker, R. Barry, D. F. Blake, P. Conrad, K. S. Edgett, B. Ferdowski, R. Gellert, J. B. Gilbert, M. Golombek, J. Gómez-Elvira, D. M. Hassler, L. Jandura, M. Litvak, P. Mahaffy, J. Maki, M. Meyer, M. C. Malin, I.

Mitrofanov, J. J. Simmonds, D. Vaniman, R. V. Welch, R. C. Wiens, Space Sci. Revs. 2012; 170, 5 .

[2] R. Rieder, R. Gellert, J. Bruckner, G. Klingelhofer, G. Dreibus, A. Yen, S.W. Squyres, J. Geophys. Res.-Planets 2003; 108, 8066.

[3] R. Gellert and B.C. Clark, Elements 2015; 11, 39.

[4] R. Gellert, R. Rieder, J. Brückner, B. C. Clark, G. Dreibus, G. Klingelhöfer, G. Lugmair, D. W. Ming, H. Wänke, A. Yen, J. Zipfel, S. W. Squyres, J. Geophys. Res.-Planets 2006; 111.E02S05, 1.

[5] J. L. Campbell, G. M. Perrett, R. Gellert, S. M. Andrushenko, N. I. Boyd, J. A. Maxwell, P. L. King, C. D. M. Schofield, Space Sci. Revs. 2012; 170, 319.

[6] NASA Planetary Data System, http://pds-geosciences.wustl.edu/missions/msl/.

[7] G. M. Perrett, J. L. Campbell, S. Glasauer, R. Pardo, X-Ray Spectrom. 2014; 43, 359.

[8] J. D. Gleason, D. A. Kring, D. H. Hill, W. V. Boynton, Geochim. Cosmochim. Acta. 1997; 61, 3503.

[9] W. G. Mumme, G. Tsambourakis, I. C. Madsen, R. J. Hill, J. Sedim. Research. 1996; 66, 132.

[10] M. Jercher, A. Pring, P. G. Jones, M. D. Raven, Archaeometry 1998; 40, 383.

[11] O. M. Rosen, A.A. Abbyasov, J. C. Tipper, Computers \& Geosciences 2004; 30, 647.

[12] J. L. Campbell, A. M. McDonald, G. M. Perrett, S. M. Taylor, Nucl. Instrum. Meth. B 2011; 269, 69.

[13] J. A. Maxwell, W. J. Teesdale J. L. Campbell, Nucl. Instrum. Meth. B 1995; 95, 407.

[14] R. W. LeMaitre, P. Bateman, A. Dudek, J. Keller, M. J. Lameyre Le Bas, P. A. Sabine, R. Schmid, H. Sorensen, A. Streckeisen, A. R. Woolley, B. Zanettin, A classification of igneous rocks and glossary of terms, Blackwell, Oxford, 1989.

[15] J. L. Campbell, P. L. King, L. Burkemper, J. A. Berger, R. Gellert, N. I. Boyd, G. M. Perrett, I. Pradler, L. M. Thompson, K. S. Edgett, R. A. Yingst, Nucl. Instrum. Meth. B. 2014; 323, 49.

[16] J. A. Nelder, R. Mead, The Comp. Journ. 1965; 7, 308. 
[17] S. Singer, J. Nelder. Nelder-Mead algorithm. Scholarpedia. 2009. url:

http://www.scholarpedia.org/article/NelderMead_algorithm (visited on 12/11/2014)

[18] L. M. Thompson, P. L. King, L. Burkemper, J. G. Spray, A. S. Yen, J. L. Campbell, G. M. Perrett, R. Gellert, A. Carnerup, J. Hamilton, S. Sommacal, and the MSL Science Team. 44th Lunar and Planetary Science Conference, abstract. 2190. The Woodlands, Texas, USA, 2013.

[19] F. J. Flanagan, T. L. Wright, S. R. Taylor, C. S. Annell, R. C. Christian, J. I. Dinnin. United States Geological Survey Professional Papers, 1976; 840, 33.

[20] K. Govindaraju, P. J. Potts, J. S. Webb, Geostandards Newsletter 1994; 18, 211.

[21] F. J. Flanagan, United States Geol. Survey Bulletin, 1986; 1582, 1.

[22] K. Govindaraju. Report (1980) on Three GIT-IWG Rock Reference Samples: Anorthosite from Greenland, AN-G: Basalte d'Essey-la-Cote, BE-N: Granite de Beauvoir, MA-N. Geostandards Newsletter 1980; 4, 49.

[23] N. Imai, S. Terashima, S. Itoh, A. Ando. 1994 Compilation of Analytical Data for Minor and Trace Elements in Seventeen GSJ Geochemical Reference Samples, "Igneous Rock Series". Geostandards Newsletter 1995; 19, 135.

[24] F.J. Flanagan. U.S. Geological Survey Silicate Rock Standards. Geochim. Cosmochim. Acta 1967; 31, 289. 


\begin{tabular}{cccccc}
\hline \multicolumn{5}{c}{ Table 1. Area occupation fractions (\%) for the five GRMs } \\
previously studied (slightly refined relative to Perrett et & al. ${ }^{[7]}$ ) \\
\hline & GA & GH & ISH-G & MDO-G & BCR-2 \\
& Granite & Granite & Trachyte & Trachyte & Basalt \\
\hline Plagioclase & 61 & 42 & 28 & 29 & 75.2 \\
Alkali Feldspar & 18 & 26 & 62 & 60 & \\
Pyroxene & & & 10 & 11 & 23.3 \\
Quartz & 14 & 27 & & & \\
Muscovite & 7 & 3 & & & \\
Chlorite & & 2 & & & 1.5 \\
Elemental Fe & & & & & \\
\hline
\end{tabular}

\begin{tabular}{|c|c|c|c|}
\hline & & APXRD & Manual \\
\hline \multirow[t]{4}{*}{ GA } & Plagioclase & $\mathrm{Ca}_{0.23} \mathrm{Na}_{0.77} \mathrm{Al}_{0.85} \mathrm{Si}_{3.15} \mathrm{O}_{8}$ & $\mathrm{Ca}_{0.3} \mathrm{Na}_{0.7} \mathrm{Al}_{0.85} \mathrm{Si}_{3.15} \mathrm{O}_{8}$ \\
\hline & K-feldspar & $\mathrm{KAlSi}_{3} \mathrm{O}_{8}$ & $\mathrm{KAlSi}_{3} \mathrm{O}_{8}$ \\
\hline & Quartz & $\mathrm{SiO}_{2}$ & $\mathrm{SiO}_{2}$ \\
\hline & Muscovite & $\mathrm{KAl}_{3} \mathrm{Si}_{3} \mathrm{O}_{10}(\mathrm{OH})_{2}$ & $\mathrm{KAl}_{3} \mathrm{Si}_{3} \mathrm{O}_{10}(\mathrm{OH})_{2}$ \\
\hline \multirow[t]{5}{*}{ GH } & Plagioclase & $\mathrm{Ca}_{0.09} \mathrm{Na}_{0.91} \mathrm{Al}_{1} \mathrm{Si}_{3} \mathrm{O}_{8}$ & $\mathrm{Ca}_{0.08} \mathrm{Na}_{0.92} \mathrm{Al}_{0.83} \mathrm{Si}_{3.18} \mathrm{O}_{8}$ \\
\hline & K-feldspar & $\mathrm{KAlSi}_{3} \mathrm{O}_{8}$ & $\mathrm{KAlSi}_{3} \mathrm{O}_{8}$ \\
\hline & Quartz & $\mathrm{SiO}_{2}$ & $\mathrm{SiO}_{2}$ \\
\hline & Muscovite & $\mathrm{KAl}_{3} \mathrm{Si}_{3} \mathrm{O}_{10}(\mathrm{OH})_{2}$ & $\mathrm{KAl}_{3} \mathrm{Si}_{3} \mathrm{O}_{10} \mathrm{~F}_{2}$ \\
\hline & Chlorite & $\mathrm{Mg}_{0.005} \mathrm{Fe}_{4.995} \mathrm{Al}_{2} \mathrm{Si}_{3} \mathrm{O}_{10}(\mathrm{OH})_{8}$ & $\mathrm{Fe}_{5} \mathrm{Al}_{2} \mathrm{Si}_{3} \mathrm{O}_{10}(\mathrm{OH})_{8}$ \\
\hline \multirow[t]{3}{*}{ ISH-G } & Anorthoclase & $\mathrm{Na}_{0.36} \mathrm{~K}_{0.64} \mathrm{AlSi}_{3} \mathrm{O}_{8}$ & $\mathrm{Na}_{0.38} \mathrm{~K}_{0.61} \mathrm{AlSi}_{3} \mathrm{O}_{8}$ \\
\hline & Augite & $\mathrm{Ca}_{0.009} \mathrm{Na}_{0.991} \mathrm{Mg}_{0.60} \mathrm{Fe}_{1.40} \mathrm{Si}_{0.5} \mathrm{Al}_{1.5} \mathrm{O}_{6}$ & $\mathrm{Ca}_{0.30} \mathrm{Mg}_{0.80} \mathrm{Fe}_{0.90} \mathrm{Si}_{1.50} \mathrm{Al}_{0 . .50} \mathrm{O}_{6}$ \\
\hline & Plagioclase & $\mathrm{Ca}_{0.56} \mathrm{Na}_{0.44} \mathrm{Al}_{1.12} \mathrm{Si}_{2.88} \mathrm{O}_{8}$ & $\mathrm{Ca}_{0.39} \mathrm{Na}_{0.61} \mathrm{Al}_{1.50} \mathrm{Si}_{2.50} \mathrm{O}_{8}$ \\
\hline \multirow[t]{3}{*}{ MDO-G } & Anorthoclase & $\mathrm{Na}_{0.51} \mathrm{~K}_{0.49} \mathrm{AlSi}_{3} \mathrm{O}_{8}$ & $\mathrm{Na}_{0.57} \mathrm{~K}_{0.40} \mathrm{AlSi}_{3} \mathrm{O}_{8}$ \\
\hline & Augite & $\mathrm{Ca}_{0.006} \mathrm{Na}_{0.994} \mathrm{Mg}_{0.45} \mathrm{Fe}_{1.55} \mathrm{SiAlO}_{6}$ & $\mathrm{Ca}_{0.2} \mathrm{Mg}_{0.60} \mathrm{Fe}_{1.20} \mathrm{Si}_{1.5} \mathrm{Al}_{0.5} \mathrm{O}_{6}$ \\
\hline & Plagioclase & $\mathrm{Ca}_{0.72} \mathrm{Na}_{0.28} \mathrm{Al}_{1.23} \mathrm{Si}_{2.77} \mathrm{O}_{8}$ & $\mathrm{Ca}_{0.6} \mathrm{Na}_{0.4} \mathrm{Al}_{1.50} \mathrm{Si}_{2.50} \mathrm{O}_{8}$ \\
\hline \multirow[t]{3}{*}{ BCR-2 } & Plagioclase & $\mathrm{Ca}_{0.54} \mathrm{Na}_{0.46} \mathrm{Al}_{1.09} \mathrm{Si}_{2.91} \mathrm{O}_{8}$ & $\mathrm{Ca}_{0.52} \mathrm{Na}_{0.48} \mathrm{Al}_{1.20} \mathrm{Si}_{2.79} \mathrm{O}_{8}$ \\
\hline & Hypersthene & $\mathrm{Mg}_{0.37} \mathrm{Fe}_{0.63} \mathrm{SiO}_{3}$ & $\mathrm{Mg}_{0.3} \mathrm{Fe}_{0.7} \mathrm{SiO}_{3}$ \\
\hline & Elemental Fe & $\mathrm{Fe}$ & $\mathrm{Fe}$ \\
\hline
\end{tabular}


Table 3. Comparison of calibration $R$-values, manual $R\left(Y_{1}\right)$ values, and APXRD

\begin{tabular}{cc|ccc|ccc}
\multicolumn{7}{c}{$R\left(Y_{1}\right)$ values } \\
\hline GRM & Type & $R$ & $\begin{array}{c}R\left(Y_{1}\right) \\
\text { APXRD }\end{array}$ & $\begin{array}{c}R\left(Y_{1}\right) \\
\text { manual }\end{array}$ & $R$ & $\begin{array}{c}R\left(Y_{1}\right) \\
\text { APXRD }\end{array}$ & $\begin{array}{c}R\left(Y_{1}\right) \\
\text { manual }\end{array}$ \\
\hline GA & Granite & 1.05 & 1.07 & 1.07 & N/A & N/A & N/A \\
GH & Granite & 1.06 & 1.08 & 1.08 & N/A & N/A & N/A \\
ISH-G & Trachyte & 1.05 & 1.03 & 1.08 & 0.80 & 0.69 & 0.81 \\
MDO-G & Trachyte & 1.07 & 1.05 & 1.11 & 0.70 & 0.68 & 0.77 \\
BCR-2 & Andesite & 1.24 & 1.22 & 1.22 & 0.71 & 0.79 & 0.79 \\
\hline & & \multicolumn{7}{c|}{$\mathrm{Al}$} & & & $\mathrm{Si}$ & \\
\hline GA & Granite & 1.08 & 1.03 & 1.03 & 0.99 & 1.04 & 1.04 \\
GH & Granite & 1.05 & 0.99 & 0.99 & 0.99 & 1.04 & 1.04 \\
ISH-G & Trachyte & 1.07 & 1.08 & 1.07 & 1.00 & 1.00 & 1.02 \\
MDO-G & Trachyte & 1.08 & 1.07 & 1.09 & 1.02 & 1.03 & 1.03 \\
BCR-2 & Andesite & 1.20 & 1.21 & 1.21 & 1.01 & 1.01 & 1.01 \\
\hline
\end{tabular}

Table 4. Effect on $R\left(Y_{1}\right)$ values for BCR-2 when pyroxene is run through APXRD as augite (test 1) and hypersthene (test 2)

\begin{tabular}{cccc}
\hline & $R$-value & $\begin{array}{c}\text { Test } 1 \\
R\left(Y_{1}\right)\end{array}$ & $\begin{array}{c}\text { Test 2 } \\
\mathrm{R}\left(Y_{1}\right)\end{array}$ \\
\hline $\mathrm{Na}$ & 1.24 & 1.11 & 1.21 \\
$\mathrm{Mg}$ & 0.71 & 0.74 & 0.82 \\
$\mathrm{Al}$ & 1.20 & 1.10 & 1.21 \\
$\mathrm{Si}$ & 1.01 & 1.02 & 1.01 \\
\hline
\end{tabular}




\begin{tabular}{|c|c|c|c|c|c|c|c|}
\hline & BHVO-2 & PM-S & WS-E & AN-G & JA-3 & AGV-2 & BT-2 \\
\hline & Basalt & Basalt & Basalt & Anorthosite & Andesite & Andesite & Basalt \\
\hline Plagioclase & 63.0 & 69.4 & 61.3 & 94.0 & 53.1 & 71.3 & 51.1 \\
\hline $\begin{array}{c}\text { Alkali } \\
\text { feldspar }\end{array}$ & & & 5.5 & & 34.0 & 7.5 & 17.6 \\
\hline Pyroxene & 37.0 & 17.3 & 14.3 & & 12.9 & 9.7 & 15.3 \\
\hline Amphibole & & 2.5 & 2.0 & 4.0 & & & \\
\hline Biotite & & 1.4 & & & & & \\
\hline Olivine & & 6.1 & & & & & 9.1 \\
\hline Quartz & & & 4.3 & 1.0 & & 11.5 & \\
\hline Analcite & & & & & & & 2.5 \\
\hline $\mathrm{Fe}-\mathrm{Ti}$ & & & & & & & 1.7 \\
\hline Spinel & & & & & & & \\
\hline Chlorite & & 3.2 & 12.5 & 1.0 & & & 2.8 \\
\hline
\end{tabular}


Table 6. Calibration $R$-values and $R\left(Y_{1}\right)$-values for the six additional GRMs and the basalt calibration target studied using APXRD-determined mineral compositions; error bars for $R$ are 2SD.

\begin{tabular}{cccccccccc}
\hline & \multicolumn{3}{c}{$\mathrm{Na}$} & \multicolumn{2}{c}{$\mathrm{Mg}$} & \multicolumn{2}{c}{$\mathrm{Al}$} \\
\hline GRM & Type & $R$ & $R\left(Y_{1}\right)$ & $R$ & $R\left(Y_{1}\right)$ & $R$ & $R\left(\underline{Y}_{1}\right)$ & $R$ & $R\left(Y_{1}\right)$ \\
\hline BHVO-2 & Basalt & $1.24 \pm 0.06$ & 1.17 & $0.81 \pm 0.03$ & 0.88 & $1.27 \pm 0.06$ & 1.26 & $0.96 \pm 0.02$ & 1.02 \\
PM-S & Basalt & $1.06 \pm 0.08$ & 1.12 & $0.85 \pm 0.04$ & 0.95 & $1.17 \pm 0.05$ & 1.14 & $0.97 \pm 0.01$ & 1.01 \\
WS-E & Basalt & $1.08 \pm 0.07$ & 1.11 & $0.85 \pm 0.04$ & 0.87 & $1.11 \pm 0.05$ & 1.12 & $1.00 \pm 0.01$ & 1.05 \\
BT-2 & Basalt & $1.18 \pm 0.07$ & 1.18 & $0.80 \pm 0.08$ & 0.88 & $1.20 \pm 0.05$ & 1.16 & $1.02 \pm 0.02$ & 1.03 \\
AN-G & Anorthosite & $0.87 \pm 0.09$ & 0.84 & $0.8 \pm 0.1$ & 0.81 & $1.02 \pm 0.04$ & 1.06 & $0.98 \pm 0.01$ & 1.01 \\
JA-3 & Andesite & $1.11 \pm 0.09$ & 1.09 & $0.68 \pm 0.04$ & 0.71 & $1.14 \pm 0.06$ & 1.05 & $0.98 \pm 0.03$ & 1.01 \\
AGV-2 & Andesite & $1.03 \pm 0.08$ & 1.09 & $0.89 \pm 0.08$ & 0.81 & $1.03 \pm 0.05$ & 1.06 & $1.01 \pm 0.03$ & 1.04 \\
\hline
\end{tabular}

